\title{
ASSESSMENT OF THE INDOOR ENVIRONMENT IN THE INTELLIGENT BUILDING
}

\author{
Luiza DĘBSKA ${ }^{1, *}$ \\ ${ }^{1}$ Faculty of Environmental, Geomatic and Energy Engineering, Kielce University of Technology, 25- \\ 314 Kielce, Poland. \\ corresponding author: Idebska@tu.kielce.pl
}

\section{Abstract}

Currently, thermal comfort and indoor air quality are essential elements in designing modern and intelligent buildings or improving existing ones, so that they would provide proper indoor conditions. The article focuses on the thermal sensations of the students of Kielce University of Technology and determining whether the given parameters of the internal environment contributed to their well-being. 164 people aged 16 - 24 participated in the study, which was conducted with the use of a microclimate meter and questionnaires. It turned out that the temperature range from $19.3{ }^{\circ} \mathrm{C}-27.6{ }^{\circ} \mathrm{C}$ is acceptable and comfortable for nearly $78 \%$ of people. As a result of further analysis, it turned out that the research group definitely prefers and feels better in colder temberatures.
\end{abstract}

\section{Keywords:}

Thermal comfort; Thermal sensations; Relative humidity; Indoor environment; Educational building.

\section{Introduction}

People all over the world are becoming more and more aware of their feelings and thermal preferences. That is why it is so important to create the best indoor environment conditions as possible, taking into account air temperature, humidity, air flow, etc. in the room. Hence, the possible introduction occurs of changes to their values in order to feel thermal comfort, if it turns out that people feel a significant discomfort. Therefore, a lot of research is carried out in various climatic zones to find out what temperature is best to choose, so that people feel good in a closed environment - at work, in public buildings, homes, hotels, schools, universities.

Experimental projects carried out in schools and universities for different climatic zones, different temperature ranges and for different age ranges of respondents can be found in literature. Rodriguez et al. [1] conducted a study of the feeling of thermal comfort at two schools in Bogota, Colombia. Assessment of thermal sensations was obtained from students aged 7 - 16 using questionnaires. In addition to the obtained questionnaires, measurements of the internal environment were carried out. The study showed that the awareness of the feeling of thermal comfort increased with the age of the participants. A different approach was presented by Abdallah et al. [2] as they undertook to evaluate and improve the thermal experience. The study site was the open space of the Faculty of Engineering, located at the University of Assiut in Egypt. The main idea of this study was to check the thermal conditions in shaded areas of open space, and then to conduct surveys, from which 118 responses were received from people currently resting between the buildings. It turned out that the students did not feel comfortable because the temperatures in the open space were too high. Therefore, it was suggested to plant more trees, which would make it possible to increase the shadows for the students and to make them more comfortable to rest. Lopez-Perez et al. [3] provided information on the feeling of thermal comfort in hot-humid climates in 27 educational buildings in the city of Tuxtla Gutierrez, Mexico. These buildings had air conditioning systems and natural ventilation. A total of 496 questionnaires were obtained. In buildings with air conditioning, $48.1 \%$ of people felt thermal comfort, for $44 \%$ it was already too cold, and for $7.9 \%$ of people it was warm. For buildings with only natural ventilation, $59.7 \%$ of people described the feeling of comfort. For $11 \%$ it was cold and for $29.3 \%$ it was warm. The authors showed that people in air-conditioned rooms prefer warmer temperatures. In United Kingdom, Jowkar et al. [4] conducted an analysis of the thermal comfort 
sensation of students studying at two universities in Coventry and Edinburgh, in differently adapted classrooms - lecture, laboratory, computer, etc. Some 3000 people took part using specially constructed questionnaires. In addition, measurements of the parameters of the internal environment were taken, regardless of whether the room was cooled or heated. The study showed that students felt better in computer rooms than in classrooms. In India, at three universities, Singh et al. [5] conducted a study involving 900 people in 30 natively ventilated classrooms. After receiving all the measurements, the average room temperature was $30.4{ }^{\circ} \mathrm{C}$, and the temperature obtained using the Griffiths method was $29.8^{\circ} \mathrm{C}$, which, according to the authors, results in a good agreement of thermal comfort predictions. In a situation where students would not feel thermal comfort, they are allowed to open windows or change clothes. Shrestha et al. [6] investigated fall thermal comfort in natural ventilated schools in Nepal, an area where the climate is temperate. A total of 818 people were examined. However, the authors proposed not one questionnaire, but three questionnaires, which the students completed after entering the classroom, then in the middle of the class and at the end of the lesson. Everything took place in 45 minutes. After analyzing the received questionnaires, for $3 / 4$ people, the temperature at which they felt comfort was on average $27^{\circ} \mathrm{C}$. In Hong Kong City, China, at the University, Fang et al. [7] studied the thermal environment of 982 students. The results showed that people whose clothing thermal resistance was less than or equal to 0.42 clo felt better in cooler temperatures. The range of thermal comfort read by the respondents ranged from $21.56{ }^{\circ} \mathrm{C}$ to $26.75{ }^{\circ} \mathrm{C}$. Jiang et al. [8] conducted winter research in Northwest China, in rural areas. 781 questionnaires were received where the parameters could be controlled and an additional 345 questionnaires where the environmental parameters were not controlled. It turned out from the obtained responses that the temperature range that best favored the well-being of the students was 13-18, while the fact of feeling comfortable in this area was determined by as many as $90 \%$ of people. An experimental study conducted by Balbis-Morejon et al. [9] at a university in a tropical climate concerned the perception of thermal comfort by selected 584 students. It was shown on the basis of the analyzed data that for $90 \%$ of people the acceptable temperature ranged from $23^{\circ} \mathrm{C}$ to $24{ }^{\circ} \mathrm{C}$. In Indonesia, at Makassar, Hamzah et al. [10] investigated the factors that most influence the well-being of primary school students. 1111 people were lost from 33 rooms from 6 different schools. The best temperature, according to students, which was conducive to learning and in a sense of comfort, was in the range of $29.1^{\circ} \mathrm{C}-30.0^{\circ} \mathrm{C}$. An analysis of the three cities of Quito, Guayaquil and Tena in Ecuador was carried out by Guevara et al. [11]. The study covered these areas due to the tropical nature of this region, and especially for the speed of weather changes that take place there. 429 questionnaires were received, of which respondents specified their thermal preferences in temperatures for Quito $21.8{ }^{\circ} \mathrm{C}$, for Guayaquil $-26.3{ }^{\circ} \mathrm{C}$ and for Tena - $26.9{ }^{\circ} \mathrm{C}$. In addition, according to the survey, respondents in the city, Guayaquil and Tena emphasized that cooler temperatures would be very satisfactory due to the climate in these two cities - hot and humid. Another example of research on thermal comfort is the research carried out by Jindal [12] in India, where the study covered 130 students aged $10-18$ years. According to the students, the range of temperatures which was comfort was equal to $15.3^{\circ} \mathrm{C}-33.7^{\circ} \mathrm{C}$. During the analysis of students' responses, it was additionally found that young people, in this case, the research group of students, showed that it is easier and faster to acclimatize in a given room, where room temperature prevails. In the vicinity of India, in Bangladesh, research has been done on the heat preferences of students by Talukdar and others [13]. 579 questionnaires of people staying in ventilated classrooms were analyzed. According to the received responses, the comfortable temperature considered as respondents was $27.8^{\circ} \mathrm{C}$. Buonocore et al. [14] investigated whether air velocity influences the feeling of thermal comfort in classrooms in Sao Luis, Brazil. The city was chosen because of its hot and humid climate with very high temperatures. The study was conducted by taking measurements of the internal environment and using questionnaires. The results showed that the students accepted the prevailing conditions in the classrooms and that air velocity had a significant impact on the perception of thermal comfort, in contrast to the relative humidity, which negatively influenced the feeling of heat. Moreover, above $31{ }^{\circ} \mathrm{C}$, the room required mechanical cooling as the increased air movement was not sufficient. The same authors, Buonocore et al. [15], continued their research on thermal comfort, but this time at Sao Luis University. The problem that the authors wanted to solve was the excessive cooling of students in lecture halls. After analyzing the students' responses, thermal preferences bordered on temperatures 23 - 24, taking into account the $20 \%$ frequency of responses experienced by discomfort when temperatures were lower than preferred, with a clo value of 0.3. Additionally, it was noticed that the students expressed a desire to raise the temperature to 26 . A similar study in a warm and humid climate was presented by Munonye [16] in a primary school in Nigeria. 180 students aged $7-12$ 
participated in the study. The research was carried out in two seasons - rainy and dry with the use of a meter and questionnaires. According to the responses of the surveyed students, the temperature of $29.1^{\circ} \mathrm{C}$ in the dry season was considered unacceptable, and for the rainy season, with an average temperature of $28.1^{\circ} \mathrm{C}$, it was considered acceptable. Great Britain was not significantly associated with a warm climate, but the changing and still warming climate caused a heatwave in Manchester, which Taleghani et al. [17] used to conduct a study in which they tested the feeling of thermal comfort indoors at the Salford University campus between May and October. It found that thermal comfort could increase if approximately $17 \%$ more trees were planted on campus. With increasing the shading, the feeling of comfort according to the research would increase by $20.8 \%$ on the hottest day. Papazoglou et al. [18] conducted an experiment combining the objective and subjective assessments of the feeling of thermal comfort by students aged $16-18$ at a school in Athens. The obtained result showed that the feelings of the respondents according to the predicted average of votes were cooler than the reality. Dębska \& Krakowiak [19] examined the perception of thermal comfort by pupils and students in selected three educational buildings in Kielce, Poland. The questionnaires were completed by 83 people in total, and the parameters of the internal environment were measured using a measuring meter. It turned out that the thermal preferences of research groups differ from commonly known standards. It was shown that the best prefered temperature was $22.5^{\circ} \mathrm{C}$, then $25.3^{\circ} \mathrm{C}$ and the lowest was $27.6^{\circ} \mathrm{C}$. Krawczyk \& Kapjor [20] checked the perception of thermal comfort by 98 people in three selected educational rooms of the Kielce University of Technology. The conclusion that can be obtained from the comparison of the respondents' answers and the norm showed that the Fanger model differs from the actual thermal sensations of the respondents. Majewski et al. [21] conducted an analysis of thermal comfort over the course of 1.5 years. A total of 1369 questionnaires were obtained and 117 rooms were examined. It turned out that the respondents described the temperature and other parameters as acceptable and directed their feelings towards higher temperatures inside the rooms. Liu \& Luo \& Cai [22] studied the feeling of the internal environment by students at Zunyi University in China, in naturally ventilated lecture halls during the winter. The temperature ranged from $11.5^{\circ} \mathrm{C}-19.8^{\circ} \mathrm{C}$. The respondents described their thermal feelings in the room as pleasantly cool and too cool, and they focused their thermal preferences on warmer temperatures. In the United States, at the University of Georgia, Aghniaey et al. [23] analyzed 11 classrooms with a temperature range of $21{ }^{\circ} \mathrm{C}-27{ }^{\circ} \mathrm{C}$. It turned out that the generally created microclimate favored the acceptability of students. When analyzing the questionnaires, the students showed no desire to change the temperature if it was approximately $23.5^{\circ} \mathrm{C}$. Krawczyk \& Surmańska [24] examined a single-family house in Poland, in the Świetokrzyskie province, for a period of two weeks, taking into account the temperature range outside from $12{ }^{\circ} \mathrm{C}$ to $24{ }^{\circ} \mathrm{C}$. Eight people participated in the study. The authors used a measuring device and questionnaires to conduct the study. From the obtained and analyzed results, it turned out that men accepted the room temperature more than women by $7.14 \%$. Nevertheless, the respondents found that they felt good in these rooms and would leave the temperature unchanged.

Despite many studies conducted in educational buildings, very few deal with modern, intelligent buildings. The present study aims to provide additional knowledge in this area, especially that modern buildings are built with new materials and technologies (as indicated by Piotrowski et al. [25]).

\section{Material and methods}

The research was carried out at Kielce University of Technology in one of the university's lecture rooms, in a building Energis, Fig. 1. It is an intelligent building equipped with a building management system (BMS). In addition, Energis is a self-sufficient building, producing energy for its own use from renewable sources such as photovoltaic panels, solar collectors, heat pumps, or windmills, etc. Moreover, each classroom is equipped with an interface that allows adjusting the temperature to the individual needs of learners or working people, or setting them at a predetermined temperature by administrators [21]. 


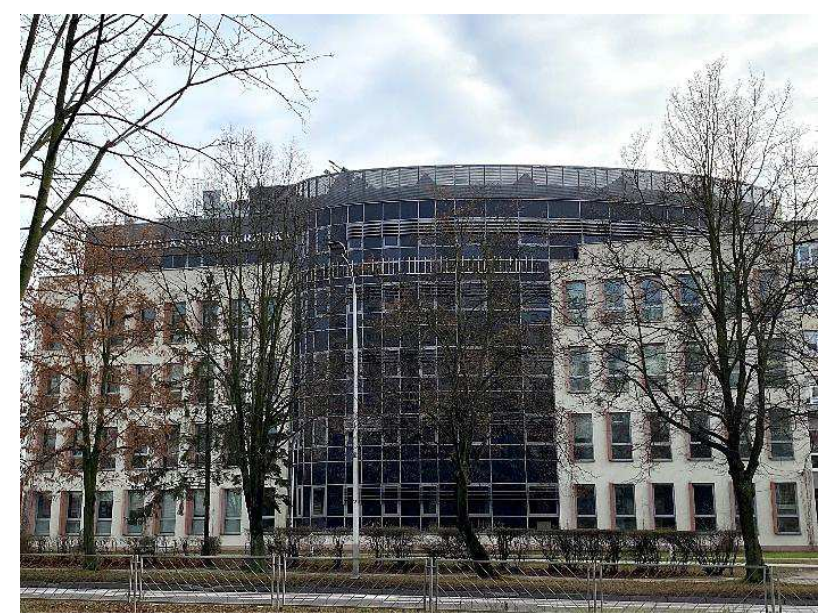

Fig. 1: Kielce University of Technology - educational and laboratory building Energis.

The study was performed in room 1.14. Before the tests, infrared inspection was carried out to determine if there are any thermal bridges or other problems that might affect the measurements. Fig. 2 presents selected digital and thermal images.
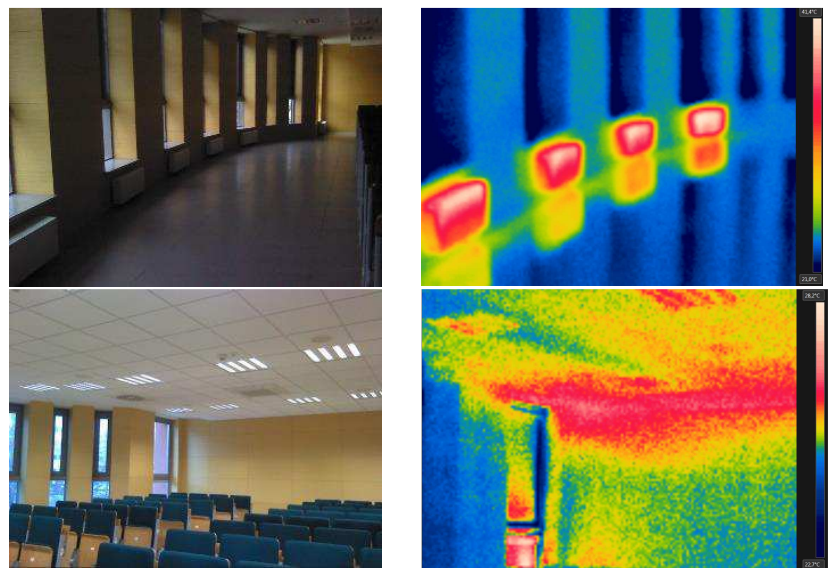

Fig. 2: Digital and infrared images of the analyzed lecture room (winter conditions).

The aim of the study was to analyze the thermal sensations of the research group and to check whether the selected parameters of the microclimate in the lecture room met the thermal expectations of these people.

The study was conducted using direct and indirect methods. The first direct method concerns questionnaires which are completed during the survey. The questionnaires individually present people's thermal preferences and inform whether a given person feels comfort or thermal discomfort. Such surveys contain questions about thermal sensations, perceived humidity, assessment of current mental productivity, assessment of light intensity, well-being and clothing. The second method is the indirect method of measuring indoor air parameters. The device used in the test is Testo 400 meter with probes. In this way, the actual parameters of the internal environment can be compared with the real feelings of the respondents, so as to better understand the process of experiencing thermal comfort and to specify the appropriate temperature range as much as possible.

During the test, the meter was placed in the center of the room. In the meantime, respondents received questionnaires which they then completed. After 15 minutes, the results were written down and then the questionnaires were collected. Fig. 3 shows the testo 400 measuring instrument.

The meter recorded the changes of indoor air parameters with time. The most significant variations occur for carbon dioxide, whose concentration increases due to breathing of the volunteers, Fig. 4. 


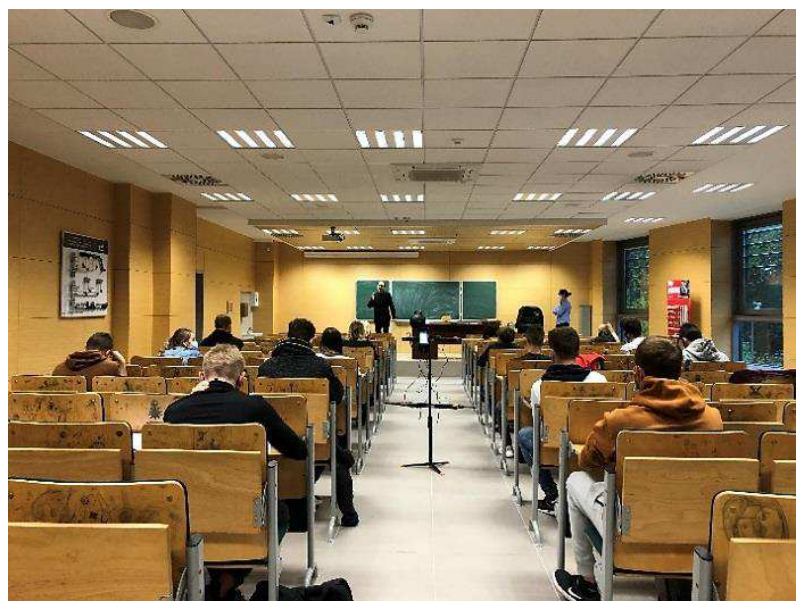

Fig. 3: Microclimate meter in the room.

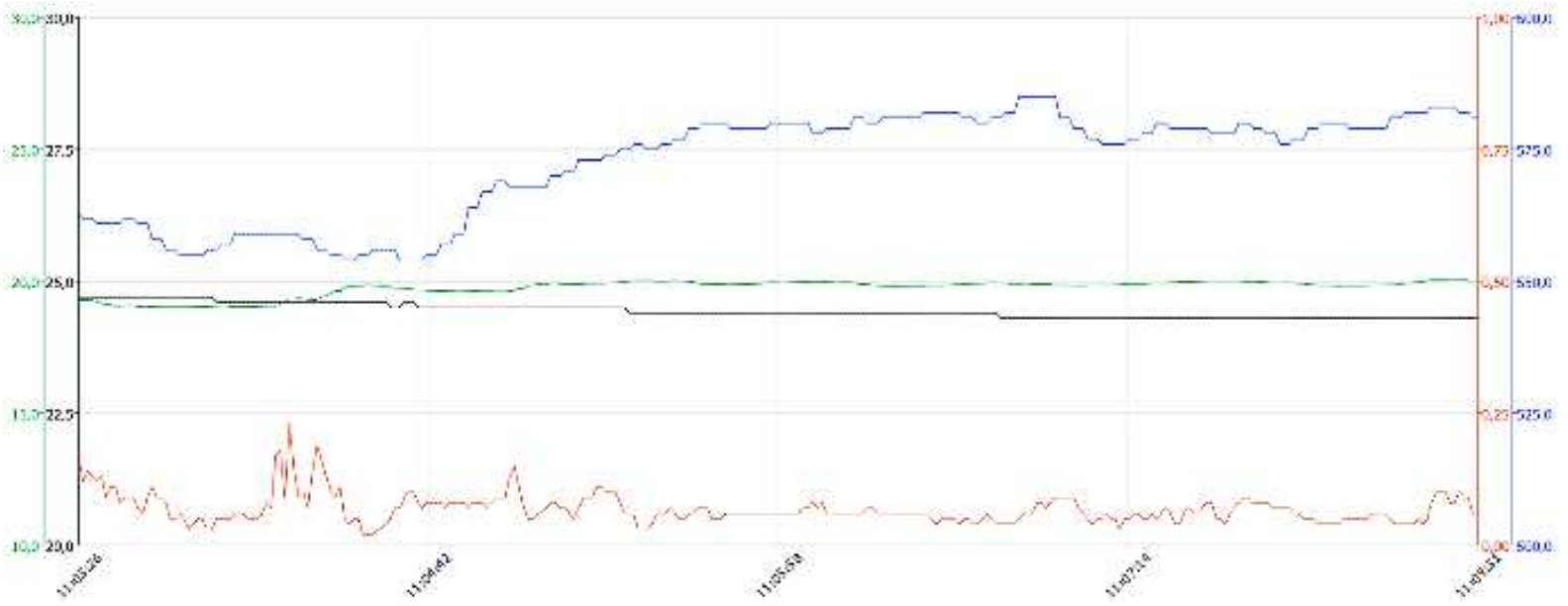

Fig. 4: Changes of air temperature (black line), humidity (green line), air velocity (red line) and $\mathrm{CO}_{2}$ concentration during selected tests (blue line).

A total of 164 people took part in the study, including 97 men and 67 women. The subjects were aged $16-24$. On the test day, the temperature was generally set by the building administrator.

\section{Results and discussion}

In total nine measurements sets were obtained. The results of indoor air parameters are presented in Table 1.

Table 1: Indoor air parameters of the nine measurements.

\begin{tabular}{|c|c|c|}
\hline Air temperature & $19.3-27.6$ & {$\left[{ }^{\circ} \mathrm{C}\right]$} \\
\hline Black sphere temperature & $19.7-26.6$ & {$\left[{ }^{\circ} \mathrm{C}\right]$} \\
\hline Relative humidity & $19.7-56.5$ & {$[\%]$} \\
\hline Air velocity & $0-0.3$ & {$[\mathrm{~m} / \mathrm{s}]$} \\
\hline $\mathrm{CO}_{2}$ concentration & $572-1255$ & {$[\mathrm{ppm}]$} \\
\hline
\end{tabular}

Generally, students were satisfied with the thermal conditions in the lecture room. Thermal sensations regarding air temperature are presented in Fig. 5 as thermal sensation vote (TSV) separately for men and women. 


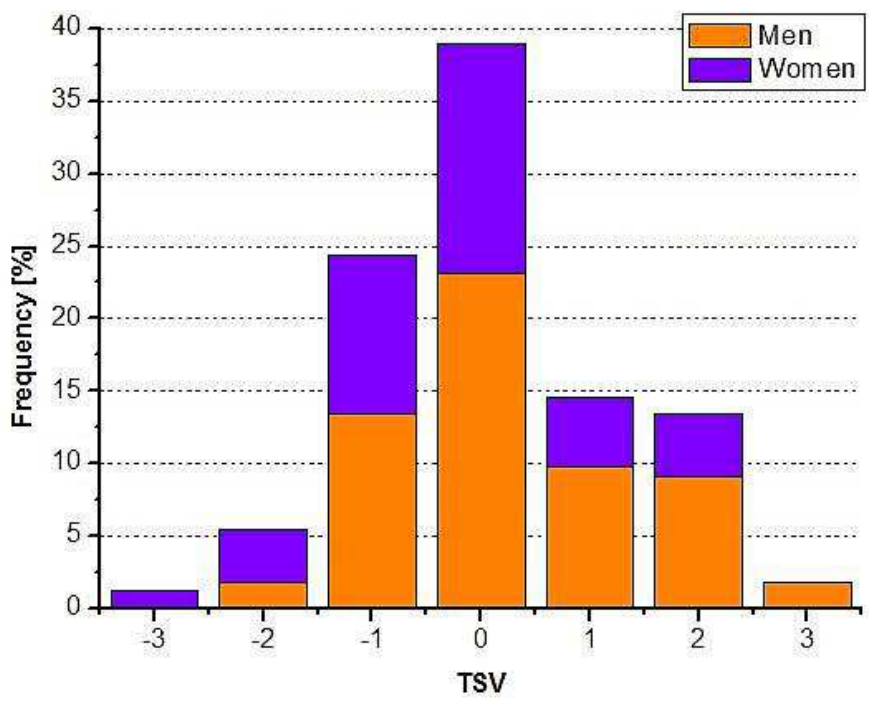

Fig. 5: Respondents' answers regarding thermal sensations: $-3-$ too cold, $-2-$ too cool, $-1-$ pleasantly cool, 0 - comfortable, 1 - pleasantly warm, 2 - too warm, 3 - too hot.

According to the respondents' answers, the most frequently given answer when describing one's thermal sensations was the answer "comfortable". The percentage of men was $23.17 \%$ and for women $15.85 \%$. Almost $1 / 4$ of the group thought that the room was "pleasantly cool" (13.41\% of men and $10.98 \%$ of women). With the votes cast for the answers "pleasantly warm" and "too warm", a similar tendency of the votes cast can be noticed. For the first and second cases, the percentage of men was $9.76 \%$ and $9.15 \%$, and for women, $4.88 \%$ and $4.27 \%$. Definitely $3.66 \%$ of women said that it was "too cold" in the room and only $1.83 \%$ of men shared the same opinion. The answers about completely extreme thermal feelings turned out to be a great surprise, which means that for $1.83 \%$ of men in the room it was "too hot", and for $1.22 \%$ of women it was "too cold". Fig. 6 shows the assessment of the current temperature in the room during the test as TAV - thermal acceptability vote.

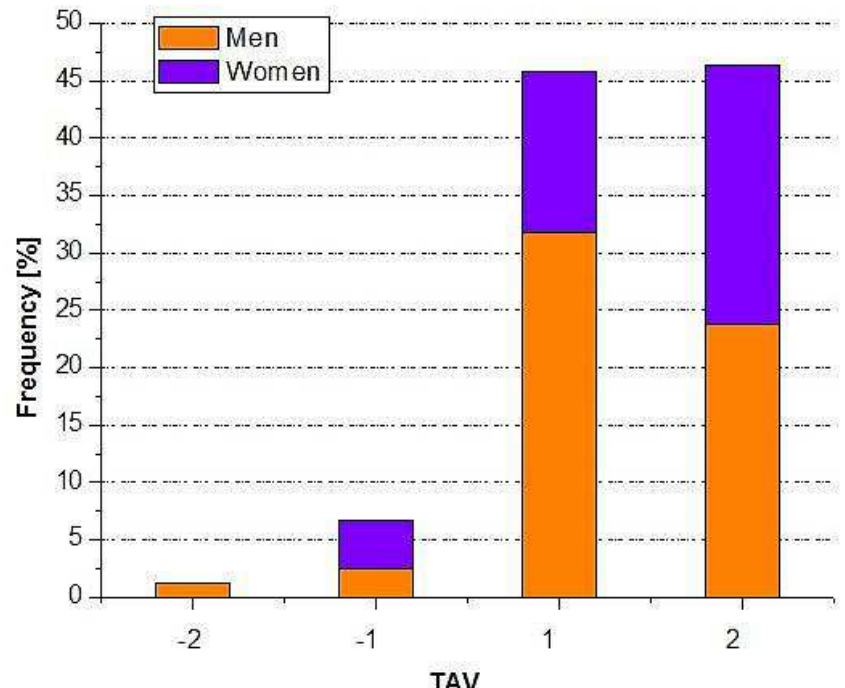

Fig. 6: Temperature assessment based on respondents' answers: -2 - definitely unpleasant, -1 unpleasant, 1 - acceptable, 2 - comfortable.

In voting over thermal acceptance, the answer "comfortably" was marked by $23.78 \%$ of men and $22.56 \%$ of women with a slight percentage difference. However, the difference between the feelings of men and women can be noticed with the votes cast for the answer "acceptable". Here the percentage of men is definitely higher than that of women, amounting to $31.71 \%$ and $14.02 \%$. For the rest of the group, the votes regarding thermal acceptability were rated as "unpleasant" $(2.44 \%$ for men, $4.27 \%$ for women) or "definitely unpleasant". The latter answer was chosen by $1.22 \%$ of men. The willingness to change the room temperature to a cooler or warmer one was expressed in Fig. 7 as TPV (thermal preference vote). 


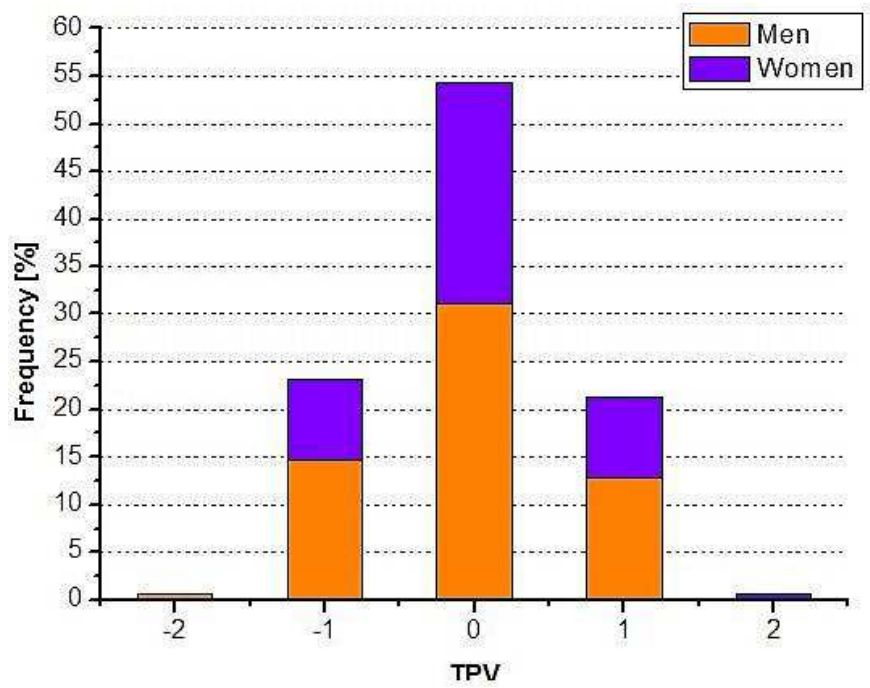

Fig. 7: Students' responses to thermal preferences: $-2-$ definitely cooler, $-1-$ cooler, $0-$ no change, 1 - warmer, 2-definitely warmer.

In the votes regarding the assessment of their thermal preferences, $54.27 \%$ of the respondents chose the answer "no change". It can be seen that there is a slight difference between the votes cast by women $23.17 \%$ and by men $31.71 \%$. Respondents' votes for "cooler" or "warmer" room temperatures were over $20 \% .14 .63 \%$ of men and $8.54 \%$ of women claimed to be "cooler", while for increasing the temperature for men it was $12.80 \%$ for women, as was $8.54 \%$ of women in the case of responses to "cooler" temperature. Moreover, $0.61 \%$ of men believe that the room could be "definitely cooler", while for $0.61 \%$ of women it could be "definitely warmer". The assessment of humidity (AHV) by the respondents is illustrated in Fig. 8.

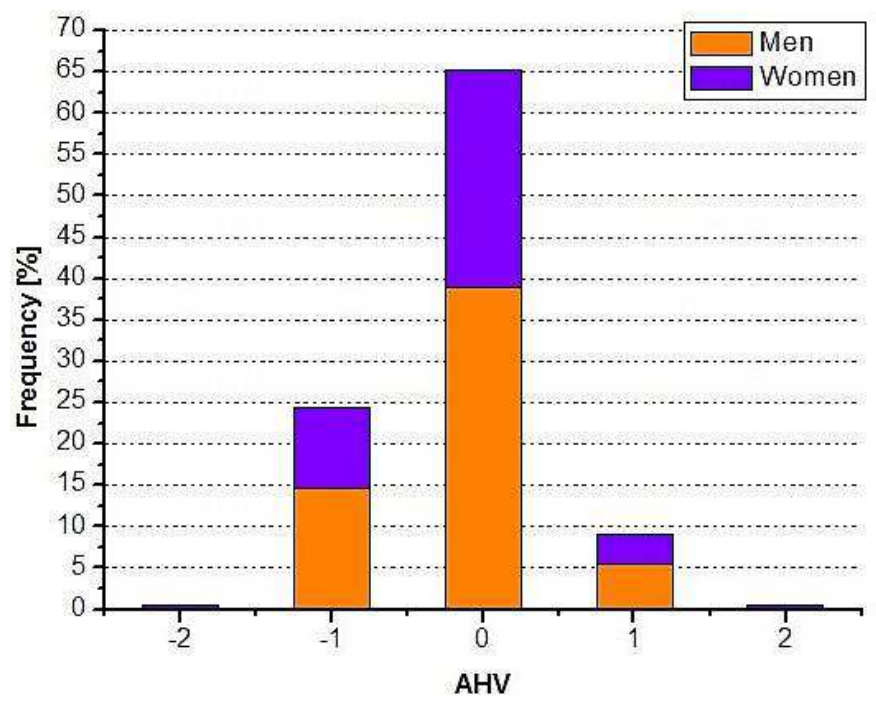

Fig. 8: Assessment of humidity vote: -2 - too dry, -1 - quite dry, 0 - pleasantly, 1 - quite humid, 2 too humid.

Relative humidity in the test room during the conducted examination was in the range $19.7 \%$ $56.5 \%$. Approximately $2 / 3$ part of the group $39.02 \%$ of men and $26.22 \%$ of women indicated the answers of the respondents to the assessment of the humidity of the internal environment in the examined room as "pleasant". According to about $1 / 4$ part of the group, the room was quite dry, with $14.63 \%$ male responses and $9.76 \%$ female responses. Only $5.49 \%$ of men and $3.66 \%$ of women found the room "quite humid". No responses were received from men that the room was "too dry" or "too humid". Such cases were recorded only in the votes of women where the same number of votes equaled $0.61 \%$ for both answers. Fig. 9 below shows the students' willingness to change the humidity to a drier or more humid one. 


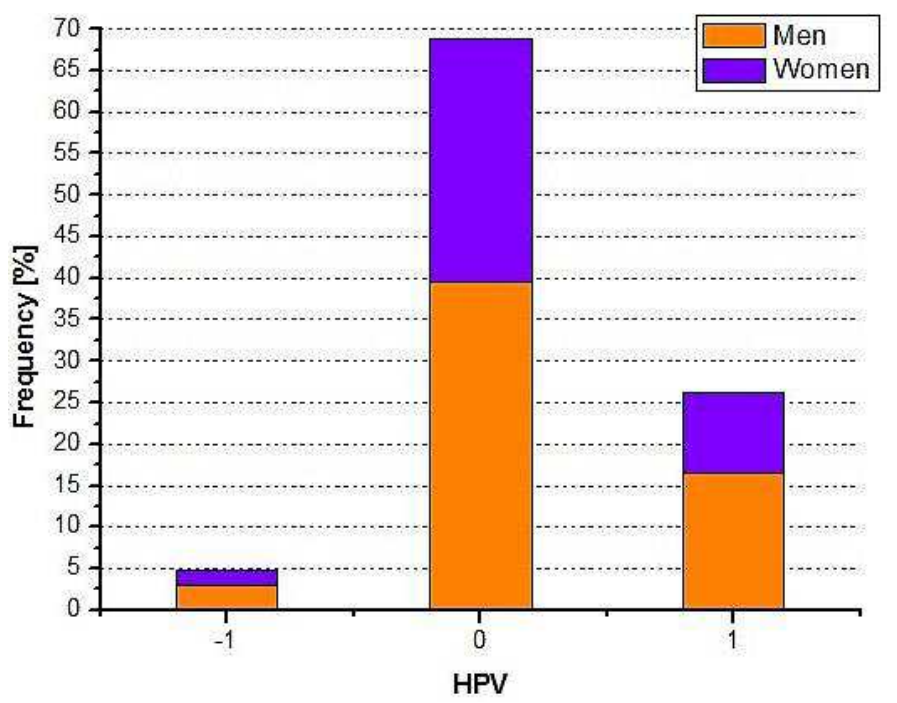

Fig. 9: Humidity preferences vote (HPV): $-1-$ more dry, 0 - no change, 1 - more humid.

About $5 / 7$ of the group would not like to make any change in humidity to a drier or more humid one. $39.63 \%$ of men and $29.27 \%$ of women declared themselves behind this answer. A small percentage of the group would like the room to be drier $3.05 \%$ of men and $1.83 \%$ of women. One quarter of the group - $16.46 \%$ of men and $9.76 \%$ of women - claimed to be more humid. From Fig. 8 and 9 it can be noticed the correctness resulting from the responses of the respondents, that is, people answering that the humidity in the room is pleasant also answered in Fig. 9 that no changes should be made. The same applies to the responses of the respondents who in Fig. 8 stated that the answer was $1 / 4$ of the group for the answer quite dry, analogically marking in the next graph 9 the answer that the room should be more humid.

In search of a relationship between the thermal preferences (TPV) and sensations (TSV) a graph has been constructed, Fig. 10.

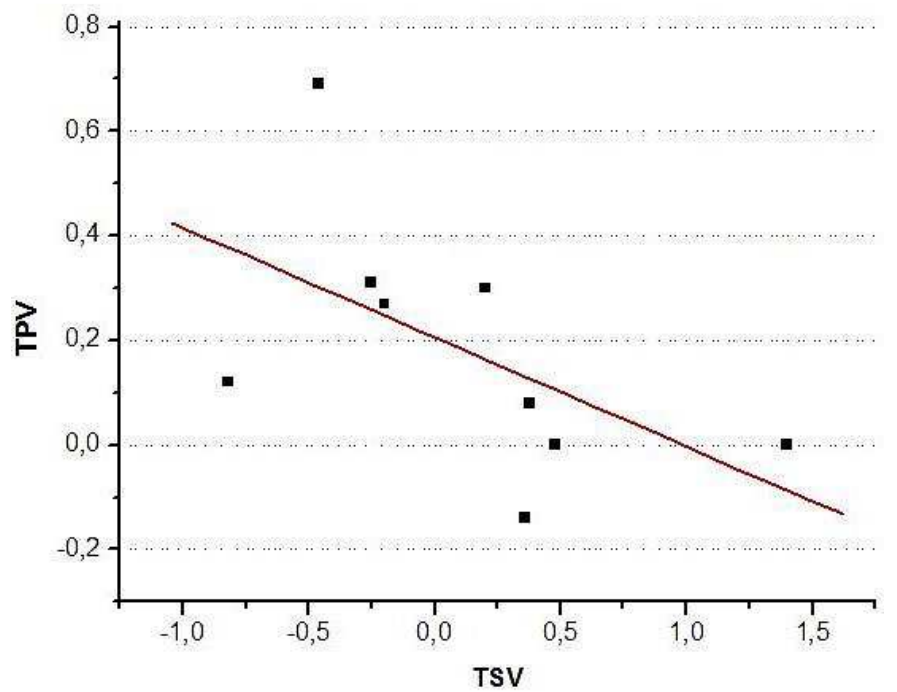

Fig. 10: The relation of average thermal preferences (TPV) and thermal sensations (TSV).

According to Fig. 10, the higher the TSV value (indicating that people feel warm or hot), the more people want the indoor environment to be cooler.

Fig. 11 below shows that the range of the highest temperature acceptability (the most preferable indoor conditions), based on the data obtained with the use of questionnaires, occurs for TSV from about -0.75 to 0.25 . 


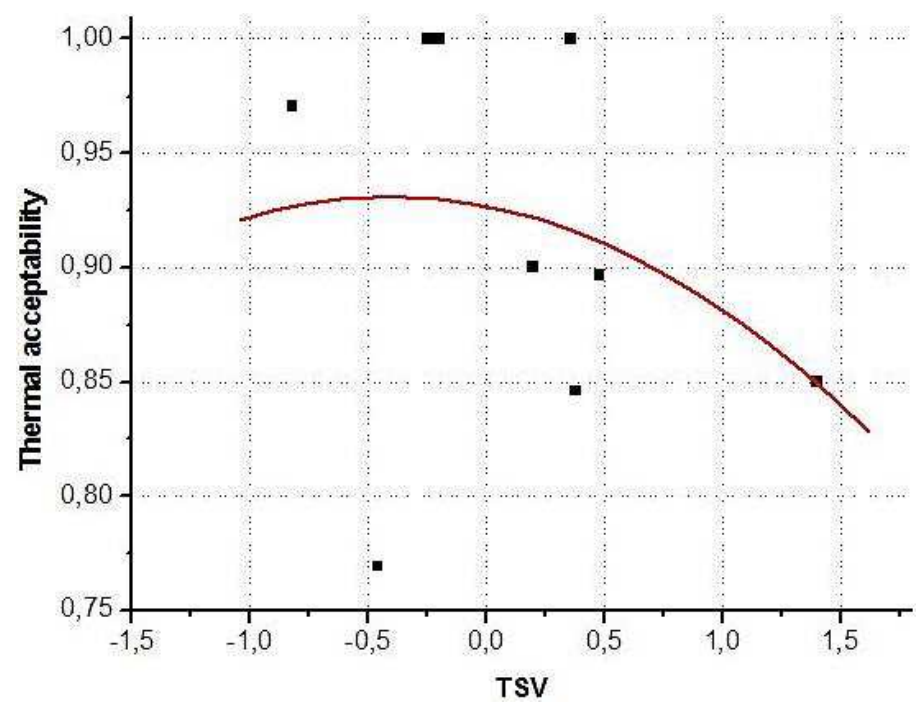

Fig. 11: The relation of thermal acceptability of the respondents vs. average thermal sensations vote (TSV)

This means that the people who took part in this study definitely prefer cooler temperatures inside the indoor environment.

\section{Conclusions}

It might be concluded that $78.05 \%$ of people experiencing temperatures in the range from $19.3^{\circ} \mathrm{C}$ to $27.6{ }^{\circ} \mathrm{C}$ described their feelings as comfortable or as pleasantly warm or cool. The rest of the people thought that the room was too warm or too cold. As a result, $92.07 \%$ of people stated that the temperature in the room is acceptable or comfortable. The humidity range from $19.7 \%-56.5 \%$ turned out to be pleasant for the study group about $65.24 \%$ of people. After analyzing the last two charts, Fig. 10 and Fig. 11, it can be concluded that students definitely prefer and feel better in cooler temperatures. On this basis, it can be concluded that the intelligent teaching and laboratory building Energis with predefined parameters of the internal environment met the thermal expectations of people. It is assumed that an intelligent building, according to its name, meets all people's expectations, whether it concerns temperature or the operation of the building installations. Therefore, in the future, the research that has already started will be continued to check other parameters such as lighting, productivity and air quality.

\section{References}

[1] RODRIGUEZ, C. M. - CORONDO, M. C. - MRDINA, J. M.: Thermal comfort in educational buildings: The Classroom-Comfort-Data method applied to schools in Bogotá, Colombia. Building and Environment, 194, 2021, https://doi.org/10.1016/j.buildenv.2021.107682.

[2] ABDALLAH, A. S. H. - HUSSEIN, S. W. - NAYEL, M.: The impact of outdoor shading strategies on student thermal comfort in open spaces between education building. Sustainable Cities and Society, 58, 2020, https://doi.org/10.1016/j.scs.2020.102124.

[3] LOPEZ-PEREZ, LA. - FLORES-PRIETO, J. J. - RIOS-ROJAS, C.: Adaptive thermal comfort model for educational buildings in a hot-humid climate. Building and Environmental, 150, 2019, pp. 181194, https://doi.org/10.1016/j.buildenv.2018.12.011.

[4] JOWKAR, M. - RIJAL, H. B. - BRUSEY, J. - MONTAZAMI, A. - CARLUCCI, S. - LANSDOWN, T. C.: Comfort temperature and preferred adaptive behaviour in various classroom types in the UK higher learning environments. Energy and Buildings, 211, 2020, https://doi.org/10.1016/ j.enbuild.2020.109814.

[5] SINGH, M. K. - KUMAR, S. - OOKA, R. - RIJAL, H. B.: Gupta G., Kumar A., Status of thermal comfort in naturally ventilated classrooms during the summer season in the composite climate of India. Building and Environmental, 128, 2018, pp. 287-304, https://doi.org/10.1016/j.buildenv. 2017.11.031.

[6] SHRESTHA, M. - RIJAL, H. B. - SHUKUVA, M.: A field investigation on adaptive thermal comfort in school buildings in the temperate climatic region of Nepal. Building and Environmental, 190, 2021, https://doi.org/10.1016/j.buildenv.2020.107523. 
[7] FANG, Z. - ZHANG, S. - CHENG, Y. - FONG, A. M. L.: OLADOKUN, M. O. - LIN Z. - WU, H.: Field study on adaptive thermal comfort in typical air conditioned classrooms, Building and Environment, 133, 2018, pp. 73-82, https://doi.org/10.1016/j.buildenv.2018.02.005.

[8] JIANG, J. - WANG, D. - LIU, Y. - DI, Y. - LIU, J.: A field study of adaptive thermal comfort in primary and secondary school classrooms during winter season in Northwest China. Building and Environmental, 175, 2020, https://doi.org/10.1016/j.buildenv.2020.106802.

[9] BALBIS-MOREJON, M. - REY-HERNANDEZ, J. M. - AMARIS-CASTILLA, C. - VELASCOGOMEZ, E. - JOSE-ALONSO, J. F. S. - REY-MARTINEZ, F. J.: Experimental Study and Analysis of Thermal Comfort in a University Campus Building in Tropical Climate. Sustainability, 12, 2020, https://doi.org/10.3390/su12218886.

[10] HAMZAH, B. - MULYADI, R. - ISHAK, M. T.: Factors Affecting Thermal Comfort of Elementary Schools' Students in Makassar. IOP Conference Series: Materials Science and Engineering, 875, 2020, https://doi.org/10.1088/1757-899X/875/1/012012.

[11] GUEVARA, G. - SORIANO, G. - MINO-RODRIGUEZ, I.: Thermal comfort in university classrooms: An experimental study in the tropics. Building and Environment, 187, 2021, https://doi.org/10.1016/ j.buildenv.2020.107430.

[12] JINDAL, A.: Thermal comfort study in naturally ventilated school classrooms in composite climate of India. Building and Environment, 142, 2018, pp. 34-46, https://doi.org/10.1016/j.buildenv. 2018.05.051.

[13] TALKUDAR, S. J. - TALUKDAR, T. H. - SINGH, M. K. - BATEN, A. - HOSSEN, S.: Status of thermal comfort in naturally ventilated University classrooms of Bangladesh in hot and humid summer season. Journal of Building Engineering, 32, 2020, https://doi.org/10.1016/j.jobe. 2020.101700.

[14] BUONOCORE, C. - VECCHI, De. R. - SCALCO, V. - LAMBERTS, R.: Influence of relative air humidity and movement on human thermal perception in classrooms in a hot and humid climate. Building and Environmental, 146, 2018, pp. 98-106, https://doi.org/10.1016/j.buildenv.2018. 09.036 .

[15] BUONOCORE, C. - VECCHI, De R. - SCALCO, V. - LAMBERTS, R.: Thermal preference and comfort assessment in air-conditioned and naturally-ventilated university classrooms under hot and humid conditions in Brazil. Energy and Buildings, 211, 2020, https://doi.org/10.1016/j.enbuild. 2020.109783.

[16] MUNONYE, C.: The Influence of Seasonal Variation of Thermal Variables on Comfort Temperature in Schools in a Warm and Humid Climate. Open Access Library Journal, 7, pp. 113, https://doi.org/ 10.4236/oalib.1106753.

[17] TALEGHANI, M. - MARSHALL, A. - FITTON, R. - SWAN, W.: Renaturing a microclimate: The impact of greening a neighbourhood on indoor thermal comfort during a heatwave in Manchester, UK. Solar Energy, 182, 2019, pp. 245-255, https://doi.org/10.1016/j.solener.2019.02.062.

[18] PAPAZOGLOU, E. - MOUSTRIS, P. K. - NIKAS, K. S. P. - NASTOS, P. T. - STATHARAS, J. C.: Assessment of human thermal comfort perception in a non-air-conditioned school building in Athens, Greece. Energy Procedia, 157 2019, pp. 1343-1352, https://doi.org/10.1016/j.egypro. 2018.11.299.

[19] DĘBSKA, L. - KRAKOWIAK, J.: Thermal environment assessment in selected Polish educational buildings. E3S Web of Conferences, 246, 15004, 2021, https://doi.org/10.1051/e3sconf/ 202124615004.

[20] KRAWCZYK, N. - KAPJOR, A.: A study of thermal comfort at Kielce University of Technology. Structure and Environment, 12, 2020, pp. 127-132, https://doi.org/10.30540/sae-2020-013.

[21] MAJEWSKI, G. - ORMAN, Ł. J. - TELEJKO, M. - RADEK, N. - PIETRASZEK, J. - DUDEK, A.: Assessment of Thermal Comfort in the Intelligent Buildings in View of Providing High Quality Indoor Environment. Energies, 13(8), 2020, https://doi.org/10.3390/en13081973.

[22] LIU, J. - LUO, Q. - CAI, T.: Students Responses to Thermal Environments in University Classrooms in Zunyi, China. IOP Conference Series: Materials Science and Engineering, 592, 2019, https://doi.org/10.1088/1757-899X/592/1/012168.

[23] AGHNIAEY, S. - LAWRENCE, T. W. - SHARPTON, T. N. - DOUGLASS, S. P. - OLIVER, T. SUTTER M.: Thermal comfort evaluation in campus classrooms during room temperature adjustment corresponding to demand response. Building and Environment, 148, 2019, pp. 488497, https://doi.org/10.1016/j.buildenv.2018.11.013.

[24] KRAWCZYK, N. - SURMAŃSKA, S.: Analysis of thermal comfort in a single-family house in Poland. Civil and Environmental Engineering, 16(2), 2020, pp. 396-404, DOI: 10.2478/cee-20200040. 
[25] PIOTROWSKI, J. ZB. - ORMAN, Ł. J. - LUCAS, X. - ZENDER - ŚWIERCZ, E. - TELEJKO, M. KORUBA, D.: Tests of thermal resistance of simulated walls with the reflective insulation, Proc. of Int. Conf. "Experimental Fluid Mechanics 2013", Czech Republic, EPJ Web of Conferences, 67, 02095, 2014. https://doi.org/10.1051/epjconf/20146702095. 